\title{
The Effectiveness of Cognitive and Psychomotor Domain of Culinary Art Students' Performance after Internship in Private Colleges
}

\author{
${ }^{1}$ Hairuddin Harun, ${ }^{2}$ Abdul Wafi Abdul Rahman, ${ }^{1}$ Noorazman A. S., ${ }^{1}$ Siti Noor Fazelah Mohd Noor, and ${ }^{2}$ Adibah \\ Aishah Md Sahak, \\ ${ }^{1}$ Universiti Tun Hussein Onn Malaysia, \\ ${ }^{2}$ Kolej Yayasan Pelajaran Johor;
}

\begin{abstract}
With the demand of culinary arts graduates in hospitality industry, more higher learning institutions especially private colleges offer the programs. The course syllabus of culinary arts is specifically designed to provide a strong foundation for students who aspire to be chefs in the local and international fields. Students are equipped with a basic education in the culinary skills and knowledge associated with the cognitive and psychomotor domain. This study investigates the influence of the cognitive and psychomotor domain effect to private college student's performance after internship. The internship program is gradually enhancing the students' knowledge; confidence level and psychomotor performance which enable them to at least gain confidence when performing their practical assessment after coming back from internship. This is a positive indication in the beginning of the students' life before expose into a real life work situation. Thus, this research can be a guidance for the private institutional lecturers to look into the effectiveness of cognitive and psychomotor domain of culinary art students' performance in their internship programs.
\end{abstract}

Keywords: Private College, Cognitive and Psychomotor Domain, Performance, Internship

\section{Introduction}

Private High Education aimed to prepare the well-balanced students with theoretical knowledge and practical skill. The industry demands more on the practical skills and knowledge for students to embark the performance of students after internship. Furthermore, according to Arokiasamy (2011), the private colleges started to escalate in Malaysia in earlier in 1996 during enforcement on the Private Universities in Malaysia.

There are 600 private higher learning institutions college that complement the work of public institutions in providing high education. Depending on the syllabus from the institutions, the comprehensive knowledge and skills can affect the performance of the student after internship. It also improves student's prospect to perform well after internship to move to another stage and level of their study. Based on their syllabus, the Bloom taxonomy is the most important guideline to the educator in leading their students' learning objective outcome after internship.
Cognitive and psychomotor domain are among being measured by educational psychologist especially on the level of skills that requires coordination of movement of their physical, knowledge and the technique to assess the students after internship (Huit, 2009). From there, the educator know the level of confident and competencies of students after internship through the assessments given after internship. According to Neuman and Banghart (2001), the relationship between college and industry is the strength to achieve the college's goals to provide the high skills and knowledge on students comparable to industry's needs

By working in the industry for the internship for a few months, students will have the opportunity to expose themselves to apply knowledge learned in the theory class and gain the practical perspectives toward work and society. Chen (2012) agreed that the theoretical knowledge and practical experiences gained during internship programs maintain a welltrained workforce. Internship program has been 
practiced for long time to develop the skills and knowledge which is beneficial to the students

Through the internship program, the institutions create the goal and objectives to ensure the students acquire the specific outcomes from the internship programmed. With certain objectives before they go for the internship program, the adequate supply of knowledge and skills must be provided. Mani (2010), stated that Internship is the vital factor in the every firm to build the right ability and capability. Cognitive and psychomotor performance after internship is important to know to what extent their practical skills and knowledge can be improved after internship and the competency of the students after internship through the assessment.

Before going to the practical places, the basic knowledge and skills during prior semester before internship have already been taught by the lecturer based on their syllabus. Yusof (2011) to examine the content of those programs as well as the strength and weakness are important.

The serious and prolonged issues of the performance of the students after internship are currently focused on skills and knowledge, the problem detected from this situation in area internship program is the lacking of students theory skills. From the observation of this situation culinary students' who came back from their internship could not answer several basic questions. For instance some subjects were learned in the Basic Western Kitchen class. Fundamental question such like "What are five basic mother sauces", "French food terminologies" could not be answered well by majority of students who just came back from their internship is became an enquiry.

This situation is aligned with the problem faced by the hotel industry, where the problems were felt profoundly in the cooking tasks (Young and Corsun, 2009). Cooking tasks requires students to possess sound background skills from culinary. From the observation, cognitive and psychomotor domain were examined toward students' performance after internship to know the level of skills and knowledge of students based on their performance. The guideline before they do the internship gives impact toward performance of students with the adequate supply of basic skills and knowledge to sustain the flexibility of students involved. Mani (2010) supported that the internship is the vital factor in the every firm to build the right ability and capability depend on the basic skills and knowledge that students learned in the syllabus.

According to Zehr (2016), internship is the process of learning for student that involved the apprenticeship, cooperative education, experimental learning, field experience, industrial and workplace learning.

The cognitive domain related with the knowledge, comprehension and application where the psychomotor domain is involving with adaptation, origination and perception. The current study is to enclose this gap and add volume to the body of knowledge through understanding the dimensions of cognitive and psychomotor domain that significantly influence the performance of students after internship.

\section{Method}

The research were conducted in three private colleges around Johor Bahru. A total of 190 of students from the Culinary Arts, based on the information given by human resource private colleges in Johor Bahru took part in the study. Krejcie and Morgans (1970) stated that in determining sample size of 127 students with total population 190 students is sufficient to collect the data. The instrumentation of this study used fivepoint Likert scale. Other than that, the scale in the Likert scale refers to the total sum of all Likert items in the questions. This research also used interval scale. Value of 1 refer to (strongly disagree) the most disagree attitude in the scale, 2 (disagree), 3 (neutral), 4 (agree) and 5 (strongly agree) the most strongly attitude in the scale. The data was then coded and keyed for analysis using a Statistical Package of Social Science (SPSS), Version 20.Analysis of variance (ANOVA) used to explain the interaction effect of domain toward performance's student after internship. Hair et al., (2007) and Pallant (2011) suggested that the idea Cronbach's alpha coefficient of a scale should be above .70 to indicate high internal consistency. Hinton (2004) suggested that an alpha score in the range of .50 to .70 is commonly accepted and considered to be criterion for demonstrating the internal consistency of reliable scale. In certain cases, a minimum reliability level of .50 was also accepted and this is consistent (Hinton, 2004). Based on Hair et al., (2007), the reliability test can also be interpreted according to the strength using the rules of thumb.

\section{Results and Discussion}

This section discussed the research objectives and research questions. The research objectives are:

a) To identify the level of the cognitive domain of Culinary Arts students' performance after coming back from the internship.

b) To identify the level of psychomotor domain of Culinary Arts students' performance after coming back from the internship.

c) To examine the predictor of the cognitive domain and psychomotor domain. 
Research Objective 1: To identify the level of the cognitive domain of Culinary Arts students' performance after coming back from the internship. This examines the first research question as well as the first hypothesis along with the three sub-hypothesis in this study:

As previously mentioned, this study exploits the standard linear regression. Cognitive domain that is a predictor for performance students after coming back from internship with the value of $(\beta=.707$, $\left.\mathrm{R}^{2}=.499\right)$. Thus, answering the first research question. This results is significant and same goes with the sub-variables, whereby it is supported with a significant unique contribution to knowledge $\left(\beta=.708, \quad \mathrm{R}^{2}=.502\right), \quad$ comprehension $\quad(\beta=.561$, $\left.\mathrm{R}^{2}=.315\right)$ and application $\left(\beta=.503, \mathrm{R}^{2}=.253\right)$.

These results proved that knowledge contains strong relationship toward performance of students after internship, following by the comprehension and application there also have a strong relationship toward the performance of students after coming back from internship.

Research Objective 2: To identify the level of the psychomotor domain of Culinary Arts students 'performance after coming back from the internship. These examine the second research question as well as the second hypothesis along with the three sub-hypothesis in this study:

As previously mentioned, these studies exploit the standard linear regression. Psychomotor domain that is a predictor for performance students after coming back from internship with the value of $\left(\beta=.525, \mathrm{R}^{2}=.275\right)$. There have a strong relationship between independent variables (psychomotor domain) and dependent variables (performance of student after coming back from internship). For the sub-variables, all the sub-variables also have the strong relationship with the contribution to adaptation $\left(\beta=.526, \mathrm{R}^{2}=.277\right)$, origination $(\beta=.359$, $\left.\mathrm{R}^{2}=.129\right)$ and perception $\left(\beta=.459, \mathrm{R}^{2}=.211\right)$.

The dimension of psychomotor domain measured in the research were involved between adaptation, origination and perception toward performance. The highest degree relationship is between adaptation and performance $(\mathrm{r}=0.34 * *$, $<0.00$ ) compared to perception and performance ( $\mathrm{r}=$ $0.21 *, \mathrm{P}=0.19)$ The very weak correlation is between origination and performance $\left(r=0.21^{*}, p\right.$ $<0.03)$ For the relationship between cognitive domain toward performance of students after coming back from internship, the beta value recorded at $.707(\mathrm{p}<0.001)$, which is higher and stronger compared to the beta value of psychomotor domain at $.525 \quad(\mathrm{p}<0.001)$ respectively were recorded. It can be concluded that performance of students after coming back from internship have stronger contribution level of cognitive domain with sub-variables knowledge, comprehension and application.

From the second variables, it also showed that psychomotor domain significantly influence the performance of students after coming back from internship. The sub-hypothesis, adaptation is highest rather than perception and origination. It is conclude that, student know how to recognize task given by lecturer and chefs based of the knowledge they have before going to internship, in effect, after coming back from internship the level of adaptation, perception and origination became stronger.

For the lecturers, the basic knowledge of theory and practical must be parallel to expose the students on the experience how to use the knowledge. Doubtlessly, knowledge is cognitive domain which one of the most important components in all three domains and in facts as the tools for students to succeed their studies. Moreover, it is the most challenging piece of academic work which determines their rate of internship.

\section{Conclusion}

From this study, it is revealed that cognitive domain which comprises of knowledge, comprehension and application are significantly influenced the performance of Culinary Arts students after coming back from internship. The findings also showed during classroom/practical class students did not fully utilized their cognitive domain. Even though skill is an important part in the culinary programs but if the students are lack at cognitive level, it will lower their performance. In fact, the ability to think, understand and apply should be practiced in order to improve their performance. It is equally important in the psychomotor, students must have all elements of psychomotor domain (adaptation, origination and perception) with the existence of cognitive domain in order to perform well. In other words if students need to have a strong skills performance, he or she need to have strong knowledge similarly to students who want to be good in a theory part, he or she must have a good skills too. Indeed, students need to have both knowledge and skills in order to be a successful and good chef in this industry.

\section{Reference}

1. Arokiasamy.A.R.A. (2011). An Analysis of Globalization and Higher Education in Malaysia. Australian Journal of Business and management research.

2. Chen. T.L \& Shen.C.C. (2012). Today's intern,tomorrow's practitioners? The influence of internship program's on student career development in the Hospitality Industry. 
3. Huit, W. Bloom et al.'s (2009) taxonomy of the cognitive domain. Educational

4. Mani, V. (2010). Evaluating effectiveness of Executive training. International Buletin of Business Administration.

5. Neuman. R.B., \& Banghart.S, (2001) Industryuniversity "consulternship": an implementation guide. International journal of education management.

6. Zehr, S. M. (2016). Student internship experience and learning opportunities: A mixed method study. University of Illinois at UrbanaChampaign,
7. Pallant, J. SPSS Survival Manual: A Step by step guide to data analysis using SPSS (4 ${ }^{\text {th }}$ Edition). Crows Nest, N.S.W: Allen \& Unwin.

8. Hair, J. F., Money, A. H., Samouel, P., \& Page, M. (2007). Research Methods for Business. West Sussex: John Wiley and Sons Limited

9. Yusof, M. F. M \& Ahmad, G (2011).Tourism and Hospitality education in Universiti Malaysia Kelantan: An Entrepreneurial Approach

10. Young, C. A \&Corsun, D. L Burned! (2009). The impact of work aspect, injury, and job satisfaction on unionized cooks' intention to leave the cooking occupation. Vol 34, Issue 1, 2010 